\title{
PrePosições: CONSTRUÇÃo DE UMA ABORDAGEM VARIACIONISTA NO ENSINO MÉDIO
}

\section{PREPOSITIONS: CONSTRUCTING A VARIATIONIST APPROACH IN UPPER SECONDARY SCHOOL TEACHING}

\author{
Elaine Marques Thomé Viegas ${ }^{1}$
}

\section{RESUMO}

Este artigo trata de uma nova abordagem das Preposições na Educação Básica, em especial, no Ensino Médio. Para tal, recomenda-se a discussão, em sala de aula, sobre heterogeneidade do sistema linguístico, variação linguística e teoria Sociolinguística. Em seguida, apresenta-se um estudo variacionista sobre a possibilidade de alternância das preposições. O artigo prossegue com a proposta de construção da abordagem desse componente gramatical para alunos do Ensino Médio. Na conclusão, retoma-se a importância tanto da pesquisa linguística para o ensino de Língua Portuguesa, quanto de uma metodologia de ensino adequada para evitar o preconceito em relação às variedades linguísticas não adquiridas na escola.

Palavras-chave: Heterogeneidade. Variação. Preposições. Ensino Médio.

\section{ABSTRACT}

This paper addresses a new approach to prepositions in primary and secondary education, particularly in upper secondary school. For that purpose it is recommended that the heterogeneity of the language system, linguistic variation and Sociolinguistic Theory should be discussed in the classroom. Then, the paper presents a variationist study of the possibility of alternating prepositions. The paper proceeds with the proposal of constructing an approach to this grammatical component for upper secondary school pupils. The conclusion resumes the importance both of linguistic research to

1 Doutora em Língua Portuguesa pela UFRJ. 
the teaching of Portuguese and of an appropriate teaching methodology to avoid prejudice in relation to language varieties not acquired at school.

Keywords: Heterogeneity. Variation. Prepositions. Upper secondary school.

\section{Introdução}

Um questionamento recorrente dos linguistas e dos professores de Língua Portuguesa é como associar os resultados verificados em fatos da língua à prescrição observada em grande número de gramáticas adotadas na Educação Básica do Brasil.

A dificuldade em conceituar o termo gramática já evidencia quão árduo é o terreno no qual professores e linguistas aventuram-se. O termo é ambíguo, podendo inclusive ser associado "à coisa física", ou seja, ao livro que traz consigo regras e princípios nem sempre tão claros como parecem (ou deveriam) ser. A atribuição de uma noção material à gramática aponta para a "coisificação", talvez pelo fato de a gramática estar "longe de nós"; em outras palavras, longe de fornecer uma explicação coerente sobre a língua usada pelos falantes, mas estar próxima a uma noção de algo "material" que fornece um modelo de uso - difícil de abranger e de compreender - que deve ser seguido pelo usuário da língua em qualquer situação de fala ou escrita. Esse distanciamento vem sendo discutido por alguns professores e pesquisadores da língua, como Barbosa (2007, p. 39) que define o conjunto de regras da gramática escolar como "uma artificialidade, um conjunto de convenções gráficas, sintáticas, de pronúncia e de variantes morfológicas, conjunto formado por gente de lugares diferentes, de momentos históricos diferentes, de estilos diferentes.".

A heterogeneidade da língua é incontestável e não se restringe à Língua Portuguesa, pois é consequência da diversidade de seus usuários e da flexibilidade intrínseca ao código linguístico. A presença de variação indica a existência de mais de uma norma, compreendida aqui como um conjunto de hábitos linguísticos. ${ }^{2} \mathrm{~A}$ heterogeneidade do sistema linguístico e a variação linguística são observadas em todas as línguas; todavia, a presença desses fenômenos não implica, necessariamente, mudança. Ao contrário, para que a mudança ocorra, é preciso que haja variabilidade e heterogeneidade.

2 Há toda uma discussão sobre o conceito de norma, em vários autores. Faraco (2008), por exemplo, estabelece três tipos de norma: (i) a culta, que designa o conjunto de fenômenos linguísticos que ocorrem habitualmente no uso dos falantes letrados em situações mais monitoradas de fala e escrita; (ii) a padrão, produto de um construto sócio-histórico que serve de referência para estimular um processo de uniformização e (iii) a gramatical, que designa o conjunto de fenômenos apresentados como cultos/comuns/standard pelos gramáticos da segunda metade do século XX, que flexibilizaram os juízos normativos, quebrando, pelo menos em parte, a rigidez da tradição excessivamente conservadora. Do ponto de vista gramatical, as variedades (as normas) são equivalentes, ou seja, todas são igualmente organizadas, todas são igualmente complexas. 
A mudança começa quando a generalização de uma alternância particular em um dado subgrupo de fala toma uma direção e assume o caráter de uma diferenciação ordenada, sendo transmitida dentro da comunidade como um todo.

Ao contrário do que se verifica na língua, a gramática normativa, adotada nas escolas, propõe a língua como algo homogêneo e imutável, como se houvesse somente uma única possibilidade de uso "normal", o uso contemplado como "correto", sem considerar a pluralidade de normas, presente tanto na fala popular, quanto na fala culta. Assim, apresenta-se um abismo entre a norma apresentada nas gramáticas, idealizada, e a norma praticada pelos usuários, determinada por relações intrínsecas à língua. Dessa forma, Callou (2007, p. 14-15) sugere uma reflexão e "uma reformulação dos conteúdos e dos procedimentos de ensino da língua, que tem, por objetivo, o domínio da chamada norma culta, sem estigmatização, contudo, das variedades linguísticas adquiridas no processo natural de socialização.”. Assim, o ensino de Língua Portuguesa deveria capacitar o aluno a reconhecer a diversidade linguística e a dominar os diferentes usos da língua, a modalidade culta de sua comunidade e as diversas formas da escrita e da fala. Além disso, deveria estimulá-lo a produzir diferentes tipos de texto e gêneros textuais, para que ele não só os compreenda, mas também compreenda os mecanismos que geram sentido nas relações de produção dos enunciados.

Em uma tentativa de diminuir o abismo entre a norma apresentada pelas gramáticas tradicionais e a norma praticada pelos usuários, norma entendida aqui como conjuntos de hábitos linguísticos, esse trabalho visa a seguir os caminhos de desconstrução de um ensino de Língua Portuguesa pautado na artificialidade e de construção de um ensino que considere a língua em uso, especialmente, no que diz respeito ao ensino de Preposições. Para tal, debate questões como heterogeneidade, variação e mudança, e faz uma pequena introdução da teoria Sociolinguística. O artigo faz ainda um recorte da dissertação de Thomé Viegas (2008) que trata da possibilidade de alternância das preposições de, em, com e para na fala culta do Rio de Janeiro. O trabalho prossegue mostrando o desenvolvimento da hipótese e os resultados da pesquisa variacionista. Por fim, sugere uma abordagem diferente da tradicional para o ensino de Preposições, no Ensino Médio.

\section{A Sociolinguística: uma teoria de análise da língua em uso}

A Sociolinguística é a área dos estudos da linguagem que estuda a língua em uso nas comunidades de fala correlacionando aspectos linguísticos e sociais, cujo objeto de análise linguística passa a ser a ( gramática da) comunidade de fala, por seu caráter essencialmente heterogêneo, e não mais a língua. 
Os linguistas Weinreich, Labov e Herzog (1968) desenvolveram um novo modelo teórico sobre a questão da mudança no livro Empirical Foundations for a Theory of Language Change para tentar responder a seguinte pergunta "Se uma língua tem de ser estruturada para funcionar eficientemente, como ela funciona se a estrutura muda?" Para respondê-la, os autores propuseram repensar o conceito de língua como sistema homogêneo e buscaram aliar estrutura à heterogeneidade, ou seja, ordem à variabilidade. Para tal, formularam um modelo capaz de contemplar a influência dos fatores sociais nos estudos da língua.

A presença de variação na língua pressupõe a existência de variantes, formas linguísticas alternantes que caracterizam um fenômeno variável. O objeto de estudo da variação constitui a variável dependente, pois o emprego de uma ou outra forma não é aleatório, e sim influenciado por fatores, chamados de grupos de fatores ou variáveis independentes, que podem ser de natureza externa - como os inerentes ao indivíduo, os sociais e os contextuais - ou de natureza interna à língua - como os fatores fonológicos, morfológicos, sintáticos, semânticos, discursivos e lexicais. Os grupos de fatores regulam, positiva ou negativamente, o emprego das formas variantes, aumentando ou diminuindo a frequência de ocorrência. O falante é capaz de lidar com esse complexo sistema sem comprometer a comunicação.

As pesquisas sociolinguísticas, frequentemente, detêm-se no nível fonológico. Lavandera (1984, p. 5) critica algumas análises que não se detêm no mesmo nível por considerar que elas não contemplam fatores externos à língua: “as análises sociolinguísticas de variação sintática que não reconhecem a influência de fatores extralinguísticos não estariam de acordo com a caracterização originária de Labov de variável linguística." A existência em um mesmo espaço de formas alternantes ou a troca sequencial de uma forma por outra não são livres e nem totalmente condicionadas por fatores extralinguísticos, mas refletem uma escolha funcional do falante com o objetivo de servir a seus propósitos comunicativos. É o que ela chama de comparabilidade funcional.

A pesquisa de Thomé Viegas (2008) utiliza a teoria Sociolinguística, nos termos da comparabilidade funcional de Lavandera (1984) com o objetivo de verificar a hipótese sugerida por Avelar (2006) de que, a depender da relação estabelecida entre os constituintes da sentença, a preposição de pode servir apenas de elo sintático, com conteúdo semântico esvaziado. Para tal, Thomé Viegas (2008) verifica a influência de fatores, internos e externos à língua, que poderiam favorecer a alternância da preposição de com as preposições em, com e para e das preposições em, com e para com de. 


\section{Alternância de preposições: hipótese e argumentos}

A relação entre os vocábulos, no latim culto, era marcada, frequentemente (i) pelas flexões de caso, expressas, algumas vezes, apenas pela diferença na quantidade da vogal final do vocábulo e (ii) pelas preposições, usadas para maior clareza ou ênfase, já que os casos morfológicos latinos eram expressos, principalmente, pelas relações funcionais entre os elementos. Com as perdas das declinações e dos casos latinos, o uso das preposições tornou-se constante, como uma forma de compensação do sistema no estabelecimento das relações entre os constituintes das sentenças e dos sintagmas. No entanto, o enriquecimento funcional foi acompanhado de um esvaziamento do significado individual das mesmas, o que pode dificultar o estabelecimento do sentido base ou originário.

Thomé Viegas (2008), com base na proposta de Avelar (2006) e na Teoria de Princípios e Parâmetros de Chomsky (1995, 2000, 2001), utiliza exemplos nos quais são verificadas diferenças entre as relações semânticas estabelecidas por de e as preposições em, com e para, com o objetivo de fundamentar a hipótese de que, em adjuntos adnominais, a preposição de seria desprovida de conteúdo semântico, o que a tornaria capaz de transitar em contextos normalmente realizados por preposições que veiculam significados diferenciados. ${ }^{3}$

Nos exemplos (01a) e (01b), os conteúdos semânticos dos sintagmas preposicionais (SPs) introduzidos por em são diversos. Enquanto em (01a) o sintagma preposicional (SP) possui o conteúdo semântico bem delineado, indicando localização, em (01b), o conteúdo é difuso, o que possibilita estabelecer diferentes relações semânticas. É possível pensar, por exemplo, em uma toalha usada para limpar a janela, ou uma toalha usada para indicar que os moradores estão em casa, ou uma toalha que é colocada na janela para secar, dentre outros. Ao contrário, de (01c) a (01h), casos em que a preposição em introduz complemento verbal e adjunto adverbial, o sentido de em costuma ser mais claro. ${ }^{4}$

3 Kato (2005a) define a linha formalista chomskiana como inatista, estruturalista e cognitivo-mentalista. Porém, ressalta que Chomsky, em vez de investigar como os enunciados estruturalmente descritos se prestam para a comunicação ou como eles retratam a nossa forma de processar a informação, procura desenhar a arquitetura da mente capaz de produzir as estruturas de uma determinada língua, ou seja, o linguista tenta desvendar a natureza do conhecimento de um adulto falante de uma língua L, ao que ele denomina língua-I - Individual, porque não vê língua como um objeto social, político ou geográfico; Interna, porque nada tem a ver com um objeto no mundo externo, mas com sua representação mental e Intensional, porque o conhecimento não se deve a um conjunto extensional de sentenças, mas a propriedades que as definem, tratando-se, portanto, de uma visão intensional de conjunto. Chomsky chama de língua-E (Externa, Extensional) o objeto de estudo que se contrapõe ao seu.

4 A autora considera complementos verbais tanto casos de objeto indireto, quanto casos de predicativo do sujeito, agente da passiva, complementos relativo e circunstancial e também os casos em que o verbo não pede complemento, mas o possui. 
(01) a. A toalha na janela precisa ser lavada. (adjunto adnominal - localização espacial)

b. A toalha da janela precisa ser lavada. (adjunto adnominal - conteúdo difuso)

c. Guardei os livros na estante.(complemento verbal - localização espacial)

d. O vizinho está em casa. (complemento verbal - localização espacial)

e. A prova será na hora da aula. (complemento verbal - localização temporal)

f. Moro no Rio de Janeiro. (complemento verbal - localização espacial)

g. Luana cortou-se na praça. (adjunto adverbial - localização espacial)

h. Pedro andou de bicicleta em Saquarema. (adjunto adverbial - localização espacial)

O sentido de com não se mostra tão preciso quanto o do item em; contudo, seu delineamento semântico ainda é mais perceptível do que o da preposição de. O uso da preposição com também possibilita o estabelecimento de um conteúdo semântico que varia do mais para o menos claro, a depender da função que a preposição introduz. Em (02a), o sentido indica posse, porém em (02b) é possível pensar em uma menina que usou o penteado em determinada festa, ou que sabe fazer um penteado, ou até, ironicamente, despenteada. De (02c) a (02e), casos de complementos verbais e adjunto adverbial, o conteúdo semântico da preposição com parece ser melhor definido.

(02) a. A menina com o penteado estava no consultório dentário. (adjunto adnominal - posse)

b. A menina do penteado estava no consultório dentário. (adjunto adnominal - conteúdo difuso)

c. Rafael está com Ana. (complemento verbal - comitatividade)

d. Flávio está com carro novo. (complemento verbal - posse)

e. Luana cortou-se com a faca. (adjunto adverbial - instrumento)

A preposição para pode manifestar conteúdos semânticos que variam entre direção, destino, finalidade e benefactividade, podendo ser resumidos pela noção de alvo. Para tende a apresentar conteúdo semântico mais difuso quando introduz complementos de determinados verbos do que quando introduz adjunto adnominal.

(03) a. O padre caminhou para a porta da igreja. (complemento verbal - direção)

b. Adélia viajou para Juiz de Fora. (complemento verbal - destino)

c. Aquela mesinha para telefone está manchada. (adjunto adnominal - finalidade)

d. A farinha pro bolo de fubá estragou. (adjunto adnominal - finalidade)

e. Comprei este livro para o meu irmão. (adjunto adnominal - benefactividade)

f. É árduo estudar para concurso. (complemento verbal - finalidade)

g. Não dá para falar com ele pelo telefone. (complemento verbal - significado impreciso) 
Segundo Avelar (2006), a imprecisão de conteúdo semântico da preposição de é revelada pela ampla possibilidade de substituí-la pelas formas em, com e para sem aparente prejuízo de sentido e apresenta três saídas para explicitar seu pensamento: ou (i) de é uma preposição polissêmica, ou (ii) existem várias preposições que se realizam como de, cada uma delas correspondendo a um sinônimo de outras preposições da língua, ou seja, há um de que veicula o valor de em, um de que veicula o valor de com, um de que veicula o valor de para e, possivelmente, de outras preposições, ou (iii) em adjuntos adnominais, de seria desprovida de conteúdo semântico, o que daria a ela a capacidade de transitar em contextos normalmente realizados por preposições que veiculam significados diferenciados.

O autor opta pela saída (iii) e classifica a preposição de como um item curinga, cujo comportamento é diferenciado das demais pelo fato de ser a mais funcional de sua categoria. Um de seus argumentos é resultado da comparação de de aos verbos leve: de corresponderia a uma preposição suporte, auxiliar. É explícito que este tipo de afirmação vai de encontro aos casos em que o item de possui uma significação mais precisa, como em adjuntos adverbiais que carregam, claramente, as noções de origem ou afastamento. Essa preposição seria capaz de comportar-se tanto como um item gramatical quanto como um item lexical podendo "carregar", dessa forma [-significado] ou [+significado]. O fato de a preposição de poder intermediar relações semânticas idênticas às relações estabelecidas pelo verbo ter transitivo em sentenças possessivas corrobora o argumento de que de seria uma preposição funcional, conforme exemplos de (04) a (07).

(04) a) A queda do dólar assusta os investidores.

b) O dólar tem queda e assusta os investidores.

(05) a) O sindicato dos trabalhadores defende a maioria.

b) A maioria dos trabalhadores tem sindicato para defendê-los.

(06) a) Os carros do casal são novos.

b) O casal tem carros novos.

(07) a) O problema do professor é o salário.

b) O professor tem o problema do salário.

A possibilidade de o item de, em preposições complexas, combinar tanto com advérbios quanto com substantivos mostra a proximidade de seu comportamento ao dos verbos leve. Na relação das locuções prepositivas, de apresenta-se como um elo sintático entre o advérbio ou o substantivo, elementos cujo significado é veiculado, e o seu complemento. Construções que expressam quantidade 
podem ser tratadas da mesma maneira; porém, em vez de combinarem com os advérbios, o item de combina com os constituintes nominais que expressam quantidade. Nesses dois casos, a preposição de exerce apenas um papel funcional, atuando como um item que permite a ligação entre a expressão de quantidade e o termo que funciona como seu complemento, em outros termos, de licencia a marcação de caso. Um fato que vai ao encontro dos casos de (08) a (11) é a possibilidade da preposição de poder ser omitida em estruturas topicalizadas, indicando que ela não contribui na construção de sentido, exercendo somente um papel gramatical.

(08) São Paulo fica abaixo do Rio de Janeiro.

a) Rio de Janeiro, São Paulo fica abaixo $(* d o)$.

(09) Minas Gerais fica acima do Rio de Janeiro.

a) Rio de Janeiro, Minas Gerais fica acima $(* d o)$.

(10) O médico disse que eu deveria tomar oito copos de água por dia.

a) Água, o médico disse que eu deveria tomar oito copos $(* d e)$ por dia.

(11) Toneladas de lixo foram retiradas do Engenhão durante o Pan.

a) Lixo, toneladas $(*$ de) foram retiradas do Engenhão durante o Pan.

Outros argumentos de Avelar (2006) que corroboram a hipótese de que de é uma preposição que não contribui na composição de sentidos em função de adjunto adnominal são (i) a possibilidade de inversão dos constituintes nominais com de sem que haja alteração no papel semântico exercido por um ou outro na relação, como nos casos (12) e (13) e (ii) a ocorrência dessa preposição em epítetos preposicionados, construções em que uma característica e um nome são intermediados pela preposição de, casos de (14) e (15). Nelas, o item de também funciona somente como um conector e a preposição não é exigida quando o nome é deslocado. $\mathrm{O}$ autor também argumenta que a preposição de é dispensada nos casos em que o adjunto adnominal é deslocado para o início da sentença, como em (16) e (17).

(12) a) O saco de bala veio rasgado.

b) A bala do saco está mole.

(13) a) O quarto da bagunça precisa de uma arrumação.

b) A bagunça do quarto precisa de uma arrumação.

(14) a) Aquele chato do meu primo comprou um lindo cachorro.

b) Meu primo, aquele chato $(* d o)$ comprou um lindo cachorro. 
(15) a) O bobão do Luís é fiador de todo mundo.

b) O Luís, aquele bobão $(* d o)$ é fiador de todo mundo.

(16) a) Só falta a faxineira limpar o box do banheiro.

b) $O$ banheiro, só falta a faxineira limpar $o$ box. $(* d o)$.

(17) a) Eu não li nenhum livro do Jorge Amado.

b) Jorge Amado, eu não li nenhum livro $(* d o)$.

Assim, após constatar as diferenças entre as relações semânticas estabelecidas por de e as preposições em, com e para, Thomé Viegas (2008), com base na proposta de Avelar (2006) e na teoria estabelecida pelos linguistas Weinreich, Labov e Herzog (1968), nos termos da comparabilidade funcional de Lavandera (1984), estabelece variáveis independentes que poderiam favorecer a alternância de preposições, alternância essa que corroboraria a hipótese de a preposição de comportarse como um item semanticamente neutro, especialmente quando introduz SP que exerce função de adjunto adnominal.

\section{As preposições de, em, com e para sob uma abordagem variacionista}

A pesquisa de Thomé Viegas (2008) verifica quais fatores, internos ou externos à língua, favorecem a alternância da preposição de com as preposições em, com e para e das preposições em, com e para com de visando a comprovação da hipótese estabelecida por Avelar (2006) de que de, como introdutora de adjunto adnominal, seria uma preposição esvaziada semanticamente, um item “curinga". Para tal, a autora utiliza dezoito inquéritos do século XX que fazem parte do acervo do Projeto Norma Linguística Urbana Culta do Rio de Janeiro (www.letras.ufrj.br/nurc-rj), distribuídos por décadas e tipo de amostra, gênero e três faixas etárias: anos setenta e noventa, esse dividido em Recontato e Amostra Complementar; masculino e feminino; 25 a 35 anos, 36 a 55 anos e 56 anos em diante. Os temas das entrevistas são variados como Cidade e comércio, Alimentação, Sindicatos e cooperativas, Vida social e diversão, dentre outros.

Para a análise dos dados, a autora aplica a metodologia da Sociolinguística quantitativa laboviana nos termos da comparabilidade funcional de Lavandera (1984). Na codificação, além da variável dependente, possibilidade de alternância, foram utilizados outros quatorze grupos de fatores, sendo dez de natureza interna e quatro de natureza externa à língua: 1. preposição do inquérito, 2. função sintática do sintagma preposicional, 3. mudança de função sintática após alternância, 4. tipo de SP quanto à presença de verbo, 5 e 6. realização de determinantes junto ao SP e ao elemento posicionado à esquerda do SP, 7 e 8. especificidade semântica (ES) do SP e do elemento posicionado à esquerda do SP, 9. preposição pela qual a do inquérito pode alternar (considerando-se somente a 
alternância entre de e outras preposições ou outras preposições por de), 10. possibilidade de paráfrase da relação nominal por uma sentença possessiva com ter, 11. faixa etária, 12. gênero, 13. década, 14. inquérito. Os dados foram submetidos ao programa computacional Varbrul (PINTZUK, 1988) e o fator analisado como variável dependente, possibilidade de alternância, é o mesmo utilizado como valor de aplicação ${ }^{5}$.

Um dos grupos verifica a preposição que encabeça o sintagma preposicional - de, em, com ou para. A opção de Thomé Viegas (2008) por analisar somente essas preposições decorre de resultados de estudos anteriores (SANTOS, A.; CAMPOS, V.; CALLOU, D., 2006a; SANTOS, A.; CAMPOS, V.; CALlOU, D., 2006b; THOMÉ, E.; ANDRADE, P.; CALLOU, D., 2005; THOMÉ, E., 2006a; THOMÉ, E., 2006b; THOMÉ, E., 2006c;), que mostraram ser essas quatro as preposições mais frequentes, tanto na escrita quanto na fala ${ }^{6}$. A autora observou se a preposição de poderia alternar com em, com e para e também se em, com e para poderiam alternar com de. A Tabela 1 expõe (i) o total de ocorrências de cada tipo de preposição analisada, (ii) quantas dessas preposições possibilitam variação, (iii) a porcentagem de variação e (iv) o total de preposições analisado: 1.002 ocorrências.

Tabela 1 - Distribuição das preposições analisadas

$\begin{array}{ccc}\begin{array}{c}\text { Preposição } \\ \text { do inquérito }\end{array} & \text { Alternam } & \begin{array}{c}\text { Total de } \\ \text { ocorrências }\end{array} \\ \text { de } & 141(28 \%) & 495 \\ \text { em } & 27(8 \%) & 333 \\ \text { com } & 5(5 \%) & 94 \\ \text { para } & 12(15 \%) & 80 \\ \text { Total } & 185(18 \%) & 1002\end{array}$

Fonte: elaboração própria

Os grupos selecionados como relevantes para a possibilidade de alternância de de com em, com e para e de em, com e para com de são (i) função sintática do SP, (ii) possibilidade de paráfrase da relação nominal por uma sentença com ter, (iii) especificidade semântica do SP e (iv) especificidade

5 Scherre (2012, p. 4) explica como atua o programa VARBRUL e define alguns termos observados nesse tipo de análise computacional "O programa VARBRUL mede o efeito relativo dos fatores das variáveis independentes ou grupo de fatores, projetando pesos relativos associados a cada fator de cada variável independente em sucessivas análises [...]. Os pesos relativos são calculados tomando a média de uma dada variante como referência, o seu input, e são grandezas que se situam entre zero e um. Os efeitos de favorecimento ou não favorecimento das variantes da variável dependente analisada, medidos pelos pesos relativos, devem ser observados em função de sua hierarquia dentro da cada etapa de análise pelo programa e não em termos de suas grandezas absolutas (SANKOFF, 1988)."

6 As gramáticas normativas apresentam uma lista com algo em torno de quinze preposições essenciais. De acordo com Cunha e Cintra (2001, p. 562-578), são elas: a, ante, até, após, com, contra, de, desde, em, entre, para, perante, por (per), sem, sob, sobre, trás. 
semântica do elemento à esquerda do SP. ${ }^{7}$

A hipótese estabelecida para analisar a função sintática do SP era a de que a função de adjunto adnominal possibilitaria maior alternância pelo fato da preposição de, nessa função sintática, possuir um significado semântico "difuso", podendo introduzir diferentes relações entre o termo regente e o termo regido. Na Tabela 2, verifica-se que as funções sintáticas tanto de adjunto adnominal, quanto de adjunto adnominal locativo são favorecedoras da alternância de preposições, resultado que confirmaria a hipótese de Avelar (2006) e de Thomé Viegas (2008).

Tabela 2 - Distribuição das alternâncias em relação à função sintática

\section{Fator Oco/Total Percentual Peso relativo (PR)}

$\begin{array}{cccc}\text { Adj. adn. locativo } & 22 / 70 & 31 \% & .71 \\ \text { Adj. Adnominal } & 114 / 399 & 29 \% & .68 \\ \text { Compl. V. prep. } & 9 / 98 & 9 \% & .39 \\ \text { Objeto indireto } & 22 / 202 & 11 \% & .35 \\ \text { Adj. adverbial } & 7 / 154 & 5 \% & .20\end{array}$

Fonte: elaboração própria

(18) acabei me aposentando como professor-chefe (vamos dizer) diretor da Cultura Inglesa \{de ( $\mathbf{e m})$ Madureira $\}$... [I018/L17-18/GM/F3 $]^{8}$ - adjunto adnominal locativo

(19) Ah, é a base $\{\boldsymbol{d e}(\sim \mathbf{e m})$ todo bolo $\}$ né, é ovo, farinha, leite, chocolate em pó, em barra ralado, e pronto, o fermento. [I002R/L103/GF/F3] - adjunto adnominal

(20) era uma casa maravilhosa... primeiro lugar... tinha um porão habitável enorme... esse porão era cheio de mistérios prum garoto... tinha locais mais escuros... quartos $\{$ de $(\sim$ para) guardados $\} ..$ [I233/L30-31/GM/F2] - adjunto adnominal

(21) (...) mas isso é o transporte na cidade... é claro que eu não gosto de andar $\{\boldsymbol{e m}(\sim \mathbf{d e})$ ônibus $\}$ em pé [I 027/AC/L 9-10/GF/F3] - complemento verbal preposicionado

(22) Pois é, (a proteína) vem $\{\boldsymbol{d a}(\sim$ na) carne $\}$, mas ovo eles, agora tão comendo (...) [I 002R/L56/ $\mathrm{GF} / \mathrm{F} 3]$ - objeto indireto

(23) sei lá, eu acho que eu aproveitei, eu tinha uma turma aqui $\{$ na ( da) rua $\},[\mathrm{I} 003 \mathrm{AC} / \mathrm{L}$ 85/GF/ F1] - adjunto adverbial lugar

7 O input geral foi .19.

8 A identificação do trecho dado como exemplo obedece às siglas, entre colchetes: $\mathrm{I}=$ inquérito (seguido do número), $\mathrm{L}=$ linhas (seguidas dos números), $\mathrm{G}=$ gênero $(\mathrm{M}$ - masculino e $\mathrm{F}$ - feminino), $\mathrm{F}$ = faixa etária (1 - 25 a 35 anos, 2 - 36 a 55 anos, 3 -56 anos em diante). 
(24) é claro que eu não gosto de andar em ônibus $\{\boldsymbol{e m}$ ( $\sim \mathbf{d e})$ pé\}... e evito tanto o quanto possível esse tipo de transporte coletivo [I027AC/L9-10/GF/F3] - adjunto adverbial modo

A relevância do grupo que controla a possibilidade de paráfrase da relação nominal por uma sentença com ter comprovaria a hipótese de esvaziamento semântico da preposição de, conforme observado na seção 2. A seleção desse grupo vai ao encontro de um dos argumentos de Avelar (2006), segundo o qual de corresponderia a uma preposição suporte, auxiliar, assim como os verbos leves. Como se observa na Tabela 3, a alternância das preposições é favorecida quando o nome possui o SP que se refere a ele, como em "um biscoitinho [de Maisena]" - biscoito tem Maisena, ao contrário do que ocorre em "o papel [da avó] é ficar quieta" - avó tem papel, caso em que o SP possui o nome.

Tabela 3 - Distribuição das alternâncias em relação à possibilidade de paráfrase da relação nominal por ter

Fator

Nome possui SP que se refere a ele

SP possui o nome a que se refere

\section{Oco/Total Percentagem}

$\begin{array}{ccc}30 / 56 & 54 \% & .72 \\ 71 / 265 & 27 \% & .45\end{array}$

Fonte: elaboração própria

(25) Eu acho que, devido ao nosso clima, uma refeição, mais frugal sem ser muito quente né, (refeição) $\{$ com ( de) pouca caloria . [I002R/L26-27/GF/F3] - nome possui adjunto que se refere a ele $\rightarrow$ refeição tem caloria

(26) Procurava fazer bastante variedade $\{\mathbf{d e}(\sim \mathbf{e m})$ fruta $\}$ né, e farinha láctea, sempre, controlada pelo pediatra né, porque é conforme a idade. [I002R/L38-39/GF/F3] - adjunto possui nome a que se refere $\rightarrow$ fruta $t e m$ variedade

O grupo que controla a especificidade semântica do SP também se mostra relevante para a alternância das preposições. As especificidades partes do corpo, material e imaterial/abstrato são as que mais possibilitam alternância, conforme Tabela 4. Esse resultado não era esperado, pois sendo a função de adjunto adnominal locativo a que mais varia, esperava-se que a especificidade espaço fosse a mais relevante em relação à possibilidade de alternância, já que em é preposição indicativa de localização no espaço.

Tabela 4 - Distribuição das alternâncias em relação à especificidade semântica do SP

$\begin{array}{cccc}\text { Fator } & \text { Oco/Total } & \text { Percentagem } & \text { PR } \\ \text { Partes do corpo } & 1 / 4 & 25 \% & .56 \\ \text { Material } & 43 / 199 & 21 \% & .56 \\ \text { Imaterial/abstrato } & 78 / 376 & 21 \% & .56 \\ \text { Espaço } & 28 / 182 & 15 \% & .49 \\ \text { Humano/animado } & 13 / 148 & 9 \% & .29\end{array}$

Fonte: elaboração própria 
(27) eu fui... éh deixando de beber Coca-Cola... via um bolo já não tinha tanto desejo de comê-lo... e... com a dor $\{$ de cabeça $\}$ eu... suspendi o remédio... [I019AC/L33-34/GF/F2] - partes do corpo

(28) me privo de tudo... menos da comida... eu estou diminuindo consumo $\{$ de ( $\sim$ em) roupas $\} \ldots$ [I019AC/L80/GF/F2] - material

(29) meu relacionamento com amigos... que eu con/considero... o maior patrimônio... da minha vida e... (foi) o que eu consegui... realizar no... nos meus anos $\{\boldsymbol{d e}(\sim \mathbf{e m}) v i d a\}$ foi um... eh ter... realmente u/um círculo... de muitos bons amigos... [I071/L14-16/GM/F3] - imaterial/abstrato

(30) eu tinha uma turma aqui $\{\boldsymbol{n a}(\sim \mathbf{d a}) r u a\}$, a gente saía pra andar de bicicleta, pra tomar sorvete na padaria, era tudo em turma, (...) [I003/L85-86/GF/F1] - espaço

(31) Então, houve a tentativa do trabalhador de se defender da opressão do patrão e começaram então a surgir as primeiras associações $\{$ de ( para) operários $\}$. [I164R/L2-3/GM/F2] - humano/animado

Outro grupo selecionado como relevante para a alternância das preposições controla a especificidade semântica do elemento à esquerda do SP, com destaque para o contexto material. A seleção desse grupo é considerada inesperada e mostra a importância do elemento à esquerda do SP para a variação entre os itens analisados.

Tabela 5 - Distribuição das alternâncias em relação à especificidade semântica do elemento à esquerda do SP

$\begin{array}{cccc}\text { Fator } & \text { Oco/Total } & \text { Percentagem } & \text { PR } \\ \text { Material } & 35 / 76 & 46 \% & .61 \\ \text { Imaterial/Abstrato } & 96 / 367 & 7 \% & .50 \\ \text { Espaço } & 6 / 21 & 29 \% & .43 \\ \text { Humano/animado } & 11 / 54 & 37 \% & .41\end{array}$

Fonte: elaboração própria

(32) eu fui criada por exemplo no sistema de pôr a mesa $\{\boldsymbol{d o}(\sim$ no $)$ lanche $\} ..$. não é? [I002/L81/GF/ F2] - material

(33) Ah, é a base $\{\boldsymbol{d e}(\sim \mathbf{e m})$ todo bolo $\}$ né, é ovo, farinha, leite, chocolate em pó, em barra ralado, e pronto, o fermento. [002R/L103/GF/F3] - imaterial/abstrato

(34) oh eu fui numa cidadezinha $\{$ em...no ( do) Rio Grande $\} ..$. que eu achei interessante... [I017AC/ L107-108/GM] - espaço

(35) a primeira refeição é a mais importante... porque o organismo está muito descansado... assimila 
melhor... e... é a mais relaxada... quantas pessoas $\{$ do $(\sim$ no $)$ povo $\}$ não saem sem ao menos um golinho de café... [I002/L3-5/GF/F2] - humano

Em fase posterior, Thomé Viegas (2008) analisa cada caso de alternância isoladamente. Na primeira etapa, verifica a variação entre de por em, com e para e, na segunda etapa, entre em, com e para por de.

Na primeira etapa, no que diz respeito à função sintática do SP, a autora observa que a alternância delem é a única que ocorre em diversas funções, não só quando introduz adjunto adnominal (65\%), mas também, adjunto adnominal locativo (20\%), complemento verbal preposicionado (11\%), adjunto adverbial (3\%) e objeto indireto (2\%). A variação de/com e de/para é verificada somente quando a preposição de introduz adjunto adnominal.

Dando continuidade, observa ainda que a possibilidade de paráfrase da relação nominal por ter ocorre em todas as alternâncias, de/em, de/com e de/para, o que comprovaria o comportamento da preposição de como o de uma preposição leve. Em de/com, na maioria das ocorrências (74\%), o nome é possuidor do adjunto, exemplos (36)-(38), em relação ao adjunto possuidor de nome (11\%). Nos casos mais frequentes, a relação estabelecida é nome = possuidor e adjunto = possuído. Já em de/em e delpara o adjunto é, na maioria das vezes, possuidor do nome ao qual se refere.

(36) sanduíche $\{\boldsymbol{d e}(\sim \mathbf{c o m})$ presunto e queijo $\}$ [I002 R/L7/GF/F3] sanduíche tem presunto e queijo (37) loja $\{$ de $(\sim \mathbf{c o m})$ comestiveis $\}[\mathrm{I133R} / \mathrm{L} 10 / \mathrm{GF} / \mathrm{F} 2] \rightarrow$ loja tem comestíveis

(38) estantes imensas $\{\boldsymbol{d e}(\sim \mathbf{c o m})$ prateleiras $\}[\mathrm{I} 133 \mathrm{R} / \mathrm{L} 15 / \mathrm{GF} / \mathrm{F} 2] \rightarrow$ estantes têm prateleiras

Quanto às especificidades semânticas dos SPs, as maiores possibilidades de alternância ocorrem em contextos imaterial/abstrato, delem (44\%) e de/para (37\%), e material, de/com (48\%). Frequentemente, a preposição com, na relação nominal, estabelece vínculo entre continente e conteúdo, o que explica o elemento introduzido por com ser, na maioria das vezes, material. Na variação del em, verifica-se somente o SP espaço, resultado esperado, já que em é a preposição indicativa de localização. Já as especificidades semânticas dos elementos posicionados à esquerda dos SPs podem ser imaterial/abstrato e material, mais frequentes, e humano espaço.

Na segunda etapa, Thomé Viegas (2008) verifica que a variação entre em/de, com/de e para/de ocorre somente quando as preposições introduzem SPs que exercem função de adjunto adnominal. Em/de e para/de também permitem alternância quando o SP introduz, respectivamente, adjunto 
adnominal locativo (63\%) e adjunto adverbial (8\%).

Quanto à possibilidade de paráfrase da relação nominal por ter, nas variações em/de e para/de, o adjunto é possuidor do nome, com frequências de $88 \%$ e 33\%, respectivamente. No que diz respeito à variação $\mathrm{com} / \mathrm{de}$, a frequência é a mesma, tanto para adjunto ou nome possuidor, $50 \%$.

Verifica-se ainda que a única especificidade semântica dos SPs que possibilita todas as alternâncias é a imaterial/abstrato - em/de (44\%), com/de (75\%) e para/de (58\%). Somente em/de ocorre nos outros contextos semânticos analisados: espaço (44\%), material (6\%) e evento (6\%).

Por fim, as especificidades semânticas do elemento à esquerda do SP. Os contextos imaterial/ abstrato e material são verificados, respectivamente, nos três tipos de alternância - $81 \%$ e $75 \% \mathrm{em} /$ de, $50 \%$ e $6 \%$ com/de e $25 \%$ e $33 \%$ para/de. Não há variação com/de em contextos humano e espaço.

Após a apreciação dos dados, a autora apresenta suas conclusões. A primeira delas diz respeito à alta frequência da preposição de, como se verifica na Tabela 6 , provavelmente devido à imprecisão de seu conteúdo semântico, o que possibilita tanto o uso, quanto a alternância em diferentes relações nominais e até em relações verbo/complemento.

Tabela 6 - Alternâncias de/em, de/com, de/para

\begin{tabular}{c|c|c|c|c|c|c|}
\hline Alternâncias & \multicolumn{2}{|c|}{ de $\sim$ em } & \multicolumn{2}{c|}{ de com } & \multicolumn{2}{c|}{ de para } \\
\hline \multirow{2}{*}{ Preposições } & de & $55(77 \%)$ & de & $27(87 \%)$ & De & $19(61 \%)$ \\
\cline { 2 - 7 } & em & $16(23 \%)$ & com & $04(13 \%)$ & para & $12(38 \%)$ \\
\hline Total & \multicolumn{2}{|c|}{$71(100 \%)$} & \multicolumn{2}{c|}{$31(100 \%)$} & \multicolumn{2}{c}{$31(100 \%)$} \\
\hline
\end{tabular}

Fonte: elaboração própria

A segunda conclusão diz respeito ao grupo função sintática do $S P$. Na maioria dos casos em que há possibilidade de alternância, a preposição introduz SP que exerce função de adjunto adnominal, embora também sejam verificados casos de alternâncias em função de adjunto adnominal locativo, adjunto adverbial - de/em e para/de - e de complementos verbais - de/em. Esse resultado vai ao encontro do que propõe Avelar (2006): nas relações de adjunção adnominal o conteúdo semântico da preposição de é difuso, o que possibilitaria a sua alternância por outras preposições.

A terceira, diz respeito a outro grupo de fatores relevante para a alternância de preposições: possibilidade de paráfrase da relação nominal por ter. A seleção do mesmo confirma o que propõe Avelar (2006) de a preposição de poder ser considerada uma "preposição leve", servindo apenas como um elo sintático entre os nomes da relação. Tanto em de/com quanto em com/de o nome é possuidor do adjunto. Isso mostra que a preposição de nessas relações não possui conteúdo semântico delineado e que as relações 
entre os constituintes são estabelecidas mais pelos próprios constituintes do que pelas preposições.

A quarta conclusão diz respeito à seleção dos grupos referentes às especificidades semânticas, tanto do SP quanto do elemento à esquerda do SP. Essa seleção aponta para a relevância da significação dos termos envolvidos na relação sintática para a variação das preposições. Especificamente em relação às especificidades dos elementos localizados à esquerda do SP, o contexto imaterial/abstrato prevalece em todas as alternâncias: delem, de/com, de/para, em/de, com/de e para/de. Esses resultados confirmam a hipótese de que o contexto semântico influencia na alternância das preposições.

E, finalmente, a ausência de condicionamento externo mostra que a alternância entre as preposições em estudo não marca prestígio ou estigma, ao contrário, por exemplo, da variação ter/ haver. Nas alternâncias das preposições entram em jogo mecanismos "construídos" no processo de aquisição da língua (KATO, 2005b). Esses mecanismos devem ser os mesmos entre os indivíduos da comunidade e não estariam sujeitos, assim, a fatores externos à gramática. Por isso, a distribuição dessas preposições na comunidade mostrou-se uniforme, nos dois momentos, assim como na fala e na escrita, a julgar pelos resultados de outros autores (SANTOS; CAMPOS; CALLOU, 2006b; THOMÉ, 2006a; THOMÉ, 2006c). O uso da preposição de, em, com ou para corresponderia a estratégias morfossintáticas distintas de uma mesma gramática, não havendo condicionamento sociolinguístico.

\section{Construção de outra abordagem em sala de aula}

Embora a proposta deste trabalho seja uma nova abordagem sobre as Preposições, não se pretende excluir a antiga abordagem já que, sendo tratada de maneira adequada e ampliada, e não somente como a apresentação de uma lista com vários itens, aumenta a capacidade de o aluno de transitar por diferentes modalidades de uso da língua, em especial, a culta. Contudo, a proposta busca que o aluno reconheça a diversidade linguística e as diversas formas de escrita e de fala, sem a estigmatização de alguma delas, possibilitando o "trânsito" do mesmo nos diferentes usos da língua. Dessa maneira, a proposta deste trabalho coaduna-se com o que afirma Barbosa (2007, p. 50): “É preciso ensinar gramática como um ponto de partida a ser complementado pelo professor, que não é apenas um porta-voz do texto escrito, mas o profissional treinado para desenvolver habilidades de codificação e decodificação dos textos orais e escritos.”. O sucesso do ensino de língua depende, muitas vezes, de como o professor encaminha o seu trabalho, desde os primeiros dias de aula.

A proposta é que, independentemente do componente gramatical abordado, o professor introduza os alunos aos temas como presença de heterogeneidade da língua e possibilidade de variação linguística. Dessa forma, os alunos teriam conhecimento de que a língua não é homogênea e de que há uma ciência, a Linguística, que estuda a linguagem humana sob diversos aspectos - 
fonético, morfológico, sintático, semântico, social e psicológico, dentre outros - e sob diferentes tipos de abordagem - social, funcional, descritivo. Assim, a expectativa é a de que se trabalhe com alunos desprovidos de estigmatização linguística e propícios a identificar e a compreender uma abordagem diferente da língua.

A pergunta é: como a discussão promovida por Thomé Viegas (2008) pode ser aplicada em sala de aula em turmas do Ensino Médio9?

A recomendação é que o professor, de forma breve, inicie a nova abordagem contrapondo as extensas listas de preposições simples das gramáticas normativas aos resultados previamente apresentados em pesquisas nas quais as preposições de, em especial, e em, com e para são as mais frequentes, tanto na língua escrita, quanto na língua falada. ${ }^{10}$

Por meio de exemplos, o professor pode verificar a possibilidade de a preposição de veicular o sentido de outras preposições, alternando-a com em, com e para, especialmente quando de introduz adjunto adnominal. A sugestão é que o professor trabalhe com a língua falada. Para isso, ele pode obter diversas entrevistas, em norma culta, já transcritas, no endereço www.letras.ufrj.br/nurc-rj. Outra sugestão seria formar pequenos grupos e propor que os alunos, com seus celulares, entrevistem um colega de classe do próprio grupo, por exemplo, durante uns vinte ou trinta minutos. Após a entrevista, é necessário transcrevê-la. Nesse momento, o professor pode mostrar, por exemplo, a presença de hesitações e a dificuldade de se compreender trechos, apontando as adversidades do trabalho com a fala.

É necessário que o professor explique que a possibilidade de de veicular o sentido de outras preposições deve-se a um esvaziamento semântico verificado após o aumento de frequência de uso das mesmas com a perda dos casos latinos, na transição do latim para o português.

Com base em Thomé Viegas (2008), o professor poderá mostrar que há fatores, no caso, internos à língua, que favorecem a veiculação de sentido, em outras palavras, a alternância, de em, com e para por de e de de por em, com e para, como a função sintática do SP, a possibilidade de paráfrase da relação nominal por uma sentença com ter, a especificidade semântica do SP e a especificidade semântica do elemento à esquerda do SP. O professor pode, além disso, exemplificar a possibilidade de de veicular o sentido de ter, funcionando apenas como um elo sintático entre os elementos regente

9 A autora sugere que a abordagem tratada neste artigo seja desenvolvida junto ao Ensino Médio. Porém, as mesmas opções metodológicas também poderiam ser utilizadas nos anos finais do Ensino Fundamental, com adaptações didáticas.

10 Essa sugestão encontra paralelo em Castilho (2000). 
e regido de uma relação nominal. É importante salientar a ausência de fatores externos à língua na possibilidade de variação entre as preposições. Isso indica que essa alternância não marca prestígio ou estigma, assim como a alternância entre ter e haver existenciais.

Segundo Callou (2007), o uso de ter por haver atinge pessoas de todos os níveis e estratos sociais e, na fala, não é sequer estigmatizado. A estigmatização ocorre, no máximo, em casos de verbo haver flexionado como em "houveram muitos acidentes ontem". Na fala culta do Rio de Janeiro, com base em dados do Projeto NURC, verifica-se o predomínio cada vez maior do ter existencial. Na década de 70 , a frequência de uso está em torno de $60 \%$ e na década de 90 , em torno de $80 \%$. Esse fenômeno não é observado somente na fala. Callou (2007, p. 26) cita a análise de Rocha (1999) que verifica a variação entre ter/haver existenciais em três jornais cariocas voltados para leitores de diferentes classes socioeconômicas - O Globo (classe A), O Dia (classe B) e Povo (classe C). Somente no jornal O Globo verificou-se o predomínio do uso de haver, em torno de 60\% (CALLOU, 2007, p. 26 e 27).

Ainda em relação à abordagem das Preposições em sala de aula, o professor também pode motivar os alunos a (i) assinalarem as preposições encontradas nas entrevistas, (ii) elaborarem alguns grupos de fatores, baseados em Thomé Viegas (2008), e (iii) codificarem as ocorrências de preposições, de modo que possam ser submetidas ao programa Goldvarb X (SANKOFF; TAGLIAMONTE; SMITH, 2005). A proposta de submissão ao programa computacional Goldvarb X deve-se ao fato de ele ser uma das versões do Varbrul (PINTZUK, 1988) para Windows, sendo assim mais palatável ao jovem, ao contrário do Varbrul, que utiliza o antigo DOS. Por último, professor e alunos podem, juntos, verificar os resultados e chegar às conclusões sobre o "corpus" utilizado por eles.

\section{Conclusão}

Em suma, a pesquisa linguística é uma ferramenta importante para o ensino de Língua Portuguesa, pois evidencia que mesmo a norma culta possui variantes que prevalecem sobre outras, mas não anulam a existência das variantes com as quais competem. Além disso, desmistifica a ideia de que na fala tudo é possível, pois mostra que há fatores que regulam os fenômenos variáveis. Ensinar gramática, gramática normativa, tradicional, não é sinônimo de ensinar o português correto porque há diversas normas, ou seja, diversos conjuntos de hábitos linguísticos. Dessa forma, defendese a apresentação do que é normal, do que é frequente no português do Brasil, sem deixar perecer o que está disponível na nossa língua, na nossa literatura, na nossa história.

O aproveitamento dos estudos linguísticos no ensino de língua promove não só o raciocínio lógico-científico do aluno, mas também a conscientização sobre suas opções linguísticas, seja 
na produção de textos orais, seja na de textos escritos. Uma metodologia de ensino adequada, consequência de uma forma realista de observar a diversidade, não só quanto às Preposições, mas também aos outros componentes gramaticais, passa pelo conhecimento dos fatores que regulam a escolha do falante, provenientes de uma competência passiva.

Vale ressaltar que a formação do professor de Língua Portuguesa deve ser revista, independentemente do nível para o qual leciona. É indispensável uma reformulação dos conteúdos e dos procedimentos de ensino de língua que visa, apenas, o domínio da norma culta. A questão não é ensinar língua padrão, mas sim, somente ensinar a língua padrão adquirida na escola. Assim, concluise que um ensino de língua pautado na não estigmatização das variedades linguísticas adquiridas fora do ambiente escolar é essencial para que novas abordagens dos componentes gramaticais cheguem às salas de aula da Educação Básica no país.

\section{REFERÊNCIAS}

AVELAR, Juanito Ornelas de. Adjuntos Adnominais Preposicionados no Português Brasileiro. 2006. 233 f. Tese (Doutorado em Linguística) - Instituto de Estudos da Linguagem, Universidade Estadual de Campinas, Campinas, 2006.

BARBOSA, Afrânio Gonçalves. Saberes gramaticais na escola. In.: VIEIRA, Silvia Rodrigues; BRANDÃO, Silvia Figueiredo (org.). Ensino de gramática: descrição e uso. São Paulo: Contexto, 2007. p. 31-54.

CALLOU, Dinah. Maria Isensee. Gramática, variação e normas. In.: VIEIRA, Silvia Rodrigues; BRANDÃO, Silvia Figueiredo (org.). Ensino de gramática: descrição e uso. São Paulo: Contexto, 2007. p. 13-29.

CASTILHO, Ataliba Teixeira de. A língua falada no ensino de português. 2 ed. São Paulo: Contexto, 2000.

CHOMSKY, Noam. The minimalist program. Cambridge, MA: The MIT Press, 1995.

CHOMSKY, Noam. Minimalist Inquiries: The Framework. In: MARTIN, Roger; MICHAELS, David; URIAGEREKA, Juan. (ed.). Step-by-step: essays in minimalist syntax in honor of Howard Lasnik. Cambridge, MA: The MIT Press, 2000. p. 89-155.

CHOMSKY, Noam. Derivation by phrase. In: KENSTOWICZ, Michael. Ken Hale: A life in language. Cambridge, MA: The MIT Press, 2001. p. 1-52. 
CUNHA, Celso; CINTRA, Lindley. Preposição. In.: . Nova Gramática do Português

Contemporâneo. 3. ed. Rio de Janeiro: Nova Fronteira, 2001. p. 555-578.

FARACO, Carlos Alberto. Norma culta brasileira: desatando alguns nós. São Paulo: Parábola, 2008.

KATO, Mary Aizawa. A contribuição chomskiana para a compreensão da aprendizagem de L2. In.: Periódico Trabalhos em Linguística Aplicada, Campinas, v. 44, n. 2, p. 185-199, jul./dez. 2005a

KATO, Mary Aizawa. A gramática do letrado: questões para a teoria gramatical. In.: MARQUES, M. A.; KOLLER, E., TEIXEIRA, J.; LEMOS, A. S. (org.). Ciências da Linguagem: trinta anos de investigação e ensino. Braga: CEHUM (Universidade do Minho), 2005b, p. 131-145.

LAVANDERA, Beatriz. Curso de Lingüistica para el analisis del discurso. Buenos Aires: Bibliotecas Universitárias, 1984. p. 9-32.

PINTZUK, S. VARBRUL Programs. 1988. Inédito

SANKOFF, David. Variables Rules. In.: AMMON, Ulrich; DITTMAR, Norbert; MATTHEIER, Klaus (org.) Sociolinguistics. New York: Academic Press, 1988. p. 119-127.

SANKOFF, David; TAGLIAMONTE, Sali.; SMITH, Eric. Goldvarb X-A multivariate analysis application. 2005. Disponível em: <http://individual.utoronto.ca/tagliamonte/Goldvarb/GV index.htm>.Acesso em: 13 out. 2019.

SANTOS, Arilma; CAMPOS, Vitor; CALLOU, Dinah Maria. A variação das preposições de e em na linguagem escrita jornalística: uma abordagem variacionista. Comunicação apresentada na XXVII JORNADA DE INICIAÇÃO CIENTÍFICA. 2006a.

SANTOS, Arilma; CAMPOS, Vitor; CALLOU, Dinah Maria. A variação de/ em na fala e na escrita: confronto entre PB/PE. Comunicação apresentada no 54 SEMINÁRIO DO GRUPO DE ESTUDOS LINGUÍSTICOS DO ESTADO DE SÃO PAULO (GEL). 2006 b.

SCHERRE, Maria Marta Pereira. Padrões sociolinguísticos do português brasileiro: a importância da pesquisa variacionista. Tabuleiro de Letras - Revista do Programa de Pós-Graduação em Estudo de Linguagens da Universidade do Estado da Bahia, n. 04, p. 01-32. 2012.

THOMÉ, Elaine; ANDRADE, Pedro; CALLOU, Dinah Maria. Sobre o uso da preposição DE e 
EM no português brasileiro: uma abordagem variacionista. In.: SANTOS, Deize (org.) Inicia Revista da Graduação em Letras da UFRJ. n. 3. Rio de Janeiro: UFRJ, Faculdade de Letras, 2005. p. 161-168.

THOMÉ, Elaine. A funcionalidade da preposição de em corpus do século XIX. 2006a. Trabalho de Mestrado. Faculdade de Letras, Universidade Federal do Rio de Janeiro, Rio de Janeiro, 2006 a.

THOMÉ, Elaine. A gramaticalização da preposição de como introdutora de complementos e adjuntos verbais. 2006b. Trabalho de Mestrado. Faculdade de Letras, Universidade Federal do Rio de Janeiro, Rio de Janeiro, 2006b.

THOMÉ, Elaine. Preposições de e em: variação nas línguas escrita e falada nos séculos XIX e XX. 2006c. Trabalho de Mestrado. Faculdade de Letras, Universidade Federal do Rio de Janeiro, Rio de Janeiro, 2006b.

THOMÉ VIEGAS, Elaine. Preposições de, em, com e para em adjuntos adnominais: uma análise variacionista. 2008. 111 folhas. Dissertação (Mestrado em Língua Portuguesa) - Faculdade de Letras, Universidade Federal do Rio de Janeiro, Rio de Janeiro, 2008.

WEINREICH, Uriel; LABOV, Weinreich; HERZOG, Marvin. Empirical foundations of a theory of language change. In: LEHMANN, Winfred; MALKIEL, Yakov (org.). Directions for Historical Linguistics. Austin: University of Texas Press. 1968.

PROJETO NORMA LINGUÍSTICA URBANA CULTA RJ. Disponível em <www.letras.ufrj.br/ nurc-rj>. Acesso em 10 de outubro de 2019. 